EVALUASI, 3(2), September 2019, ISSN 2580-3387 (print) |

ISSN 2615-2886 (online)

Homepage : http://e-journal.staima-alhikam.ac.id/index.php/evaluasi

DOI $\quad:$ http://doi.org/10.32478/evaluasi.v3i2.296

Article type : Review Article

\title{
Relevansi Teknologi Pendidikan dan Mutu Pendidikan
}

\author{
Oleh \\ Zaedun $\mathrm{Na}^{\prime} \mathrm{im}$ \\ Dosen STAI Ma'had Aly Al-Hikam Malang
}

\begin{abstract}
The quality of education is an important issue in the world of education, because by looking at the quality of education can be a reflection of the success of education that is carried out. If the quality of education is good, it can be said that in the implementation of good education, likewise if the quality of education is low, then it can be assumed that in the implementation of education there are serious problems. Therefore this paper was appointed to inspire education observers to pay more attention in maintaining and overseeing the quality of education so that the output or graduates can be relied upon. The research method of this article uses qualitative. While presenting data using descriptive analysis and designed using a library research approach by looking for literature that discusses education technology and education quality. The results of this research are the relevance or relationship between educational technology and the quality of education, because the quality of education regarding everything that is achieved by achieving good quality education in terms of student achievement, teaching quality, and school performance can be achieved well through an educational technology approach. That is because with educational technology involving people who have
\end{abstract}

Email address: zaedunnaim82@gmail.com

EVALUASI: Jurnal Manajemen Pendidikan is licensed under

The CC BY License (https://creativecommons.org/licenses/by-sa/4.0/) 
an important role in the educational problem, then it is regulated by existing procedures and the next stage is organized to be analyzed and found solutions to solve it Key word: relevance, quality of education, educational technology

\begin{abstract}
Abstrak
Mutu pendidikan menjadi pokok permasalahan yang penting di dunia pendidikan, karena dengan melihat mutu pendidikan bisa menjadi cerminan keberhasilan pendidikan yang dijalankan. Jika mutu pendidikan bagus, maka bisa dikatakan dalam pelaksanaan pendidikan bagus, begitu pula jika mutu pendidikan rendah, maka bisa diasumsikan dalam pelaksanaan pendidikan ada permasalahan yang serius. Oleh karenanya tulisan ini diangkat guna menggugah pemerhati pendidikan untuk lebih memberikan perhatian dalam menjaga dan mengawal mutu pendidikan sehingga output atau lulusannya bisa diandalkan. Metode penelitian artikel ini menggunakan kualitatif. Sedangkan Penyajian data menggunakan deskriptif analisis dan dirancang dengan menggunakan pendekatan pustaka (library research) dengan mencari literatur yang membahas tentang teknolgi pendidikan dan mutu pendidikan. Hasil dari penelitain ini adalah adanya relevansi atau keterkaitan antara teknologi pendidikan dengan mutu pendidikan, karena mutu pendidikan berkenaan dengan segala yang menjadi tercapainya pendidikan bermutu baik dari segi prestasi siswa, kualitas mengajar, maupun kinerja sekolah bisa tercapai dengan baik melalui pendekatan teknologi pendidikan. Hal itu dikarenakan dengan teknologi pendididikan melibatkan orang-orang yang memiliki peran penting pada permasalahan pendidikan tersebut, kemudian diatur dengan prosedur yang ada dan tahap selanjutnya diorganisasi untuk dianalisis dan dicarikan solusi pemecahannya
\end{abstract}

Kata kunci: relevansi, mutu pendidikan, teknologi pendidikan 
EVALUASI, 3(2), September 2019, ISSN 2580-3387 (print) |

ISSN 2615-2886 (online)

http://doi.org/10.32478/evaluasi.v3i2.296

\section{A. PENDAHULUAN}

Rendahnya mutu pendidikan di Indonesia secara umum dan mutu pendidikan tinggi bisa dilihat dalam 2 perspektif. Pertama perspektif Makro, yakni banyak faktor yang mempengaruhi mutu pendidikan, diantaranya faktor kurikulum, kebijakan pendidikan, fasilitas pendidikan, aplikasi teknologi informasi dan komunikasi dalam dunia pendidikan. Kedua perspektif mikro atau tinjauan secara sempit dan khusus, faktor dominan yang berpengaruh dan berkontribusi besar terhadap mutu pendidikan ialah guru yang professional dan guru yang sejahtera. ${ }^{1}$

Dan peningkatan mutu atau kualitas pembelajaran merupakan inti dari reformasi pendidikan di Negara manapun. Hal ini disebabkan oleh asumsi bahwa, peningkatan mutu sekolah yang memiliki peran penting dalam peningkatan mutu pendidikan nasional, tergantung pada kualitas pembelajaran. Namun, peningkatan kualitas pembelajaran sangat bersifat kontekstual, sangat dipengaruhi oleh kondisi sosial dan kultur sekolah dan lingkungannya. Berbagai penelitian menunjukkan bagaimana pentingnya kondisi lingkungan sekolah mempengaruhi kualitas pembelajaran dan kesemuanya bermuara pada suatu pernyataan apabila ingin meningkatkan kualitas pembelajaran, kualitas sekolah sebagai satu kesatuan di mana pembelajaran berlangsung harus ditingkatkan ${ }^{2}$

Oleh karenanya mutu pendidikan diupayakan dengan segala upaya agar mutu pendidikan semakin meningkat, sehingga output atau lulusan pendidikan bisa memiliki kualitas yang baik dan mampu bersaing di era saat ini yakni era industry 4.0. Dan salah satu bentuk upaya untuk menjaga mutu pendidikan dengan jalan melalui teknologi pendidikan. Hal ini diperlukan karena ketika bicara output atau lulusan pendidikan, maka tertuju pada bagaimana proses belajar mengajarnya di kelas.

\footnotetext{
${ }^{1}$ Abdul Hadis dan Nurhayati B. Manajemen Mutu Pendidikan ( (Bandung: Alfabeta, 2010) hlm 3

2 Zamroni. Dinamika peningkatan mutu. (Yogyakarta: Gavin Kalam Utama, 2011) hlm 137-138
} 
Berkenaan hal tersebut cara yang tepat untuk mewujudkan belajar mengajar yang baik dengan jalan melalui pendekatan teknolgi pendidikan. Dengan teknolgi pendidikan akan bisa dicarikan akar permasalahan dan solusi mengatasi permasalah tersebut.

Berkenaan dengan tersebut artikel ini akan menguraikan dan menganalisis kaitannya relevansi teknologi pendidikan dan mutu pendidikan, sehingga bisa diambil pemahaman yang lebih komprehensif berkenaan dengan relevansi teknologi pendidikan dan mutu pendidikan

\section{B. KAJIAN TEORI}

\section{Teknologi Pendidikan}

a. Teknologi

Menurut beberapa pendapat, bahwa teknologi dipahami hanyalah sepanjang menyangkut soal permesinan. Selama ini kita menganggap bahwa teknologi memang sudah menjadi bagian dari kehidupan sehari-hari. Kita terbiasa dan cenderung menganggap teknologi sebagai peralatan dan berkaitan dengan mesin, komputer dan serba elektronik. Padahal arti teknologi sangat luas dan tergantung peran teknologi itu sendiri bagi manusia. ${ }^{3}$

Finn (1960) seperti yang dikutip oleh Gentry menyatakan, "selain diartikan sebagai mesin, teknologi bisa mencakup proses, sistem, manajemen, dan mekanisme pantauan; baik manusia itu sendiri atau bukan, serta secara luas, cara pandang terhadap masalah berikut lingkupnya, tingkat kesukaran, studi kelayakan, serta cara mengatasi masalah secara teknis dan ekonomis. ${ }^{4}$

Dalam hal yang sama, ia mengutip pula konsep Simon (1983) "teknologi sebagai disiplin rasional, dirancang untuk meyakinkan manusia akan keahliannya menghadapi alam fisik atau lingkungan

\footnotetext{
${ }^{3}$ Maswan dan Khoirul Muslimin. Teknologi pendidikan: penerapan pembelajaran yang sistematis. (Yogyakarta: Pustaka pelajar, 2017) hlm 23

${ }^{4}$ Ibid hlm 24
} 
EVALUASI, 3(2), September 2019, ISSN 2580-3387 (print) |

ISSN 2615-2886 (online)

http://doi.org/10.32478/evaluasi.v3i2.296

melalui penerapan hukum atau aturan ilmiah yang telah ditentukan"

Pemikiran Sattler tidak jauh berbeda dengan Finn dan Simon. la mengutip asal katanya-techne dalam bahasa Yunani, dengan makna seni, kerajinan tangan, atau keahlian. Kemudian ia menerangkan bahwa teknologi bagi bangsa Yunani kuno diakui sebagai suatu kegiatan khusus, dan sebagai pengetahuan. Menurut Paul Saettler (1968) selain mengarah pada permesinan, teknologi meliputi proses, sistem manajemen dan mekanisme kendali manusia dan bukan manusia.

Pendapat Saettler Ini mengacu pada konsep Mitcham. la mencantumkan uraian Aristoteles tentang techne sebagai penerapan (ilmu) pengetahuan sistematis agar menghasilkan kegiatan (manusia) yang baik.

Pendapat Heinich, Molenda, dan Russell (1993) memperkuat asumsi sebelumnya. Menurut mereka, "teknologi merupakan penerapan pengetahuan yang ilmiah, dan tertata. Teknologi sebagai suatu proses atau cara berpikir bukan hanya produk seperti computer, satelit dan sebagainya. Ketiga pakar ini membedakan antara teknologi yang menggunakan perangkat lunak (soft technology) dengan teknologi yang menggunakan perangkat keras (hard technology). Selain itu, mereka menyatakan "teknologi sebagai suatu pengetahuan diterapkan oleh manusia untuk mengatasi masalah dan melaksanakan tugas dengan cara sistematis dan ilmiah ${ }^{5}$

Dari beberapa pendapat diatas bisa diambil kesimpulan bahwa yang dikehendaki dari teknologi adalah sesuatu yang diterapkan oleh manusia untuk mengatasi masalah secara sistematis dan ilmiah, serta sesuatu yang bukan hanya fokus pada produk saja namun juga cara berpikirnya

\footnotetext{
${ }^{5}$ Maswan dan Khoirul Muslimin. Teknologi ... hlm 24-25
} 
EVALUASI, 3(2), September 2019, ISSN 2580-3387 (print) |

ISSN 2615-2886 (online)

http://doi.org/10.32478/evaluasi.v3i2.296

b. Pendidikan

Definis kata pendidikan, dapat diuraikan dari terminology kata pen-didik-an. Asal kata didik adalah dari kata kerja mendidik berarti memelihara dan memberi latihan (ajaran, pimpinan) mengenai akhlak dan kecerdasan pikiran. Asal kerja didikan (kamus besar bahasa Indonesia:2002) yang berarti (1) hasil mendidik, (2) yang dididik, (3) cara mendidik ${ }^{6}$

Pendidikan diartikan sebagai proses pengubahan sikap dan tata laku seseorang atau kelompok orang dalam usaha mendewasakan manusia melalui upaya pengajaran dan latihan; proses perbuatan dan cara mendidik

Pendidikan adalah pembentukan manusia suatu proses pembentukan manusia agar dapat menjalankan dan memenuhi tujuan hidupnya secara lebih efektif dan efisen.

Pada posisi tertentu pendidikan berbeda dengan pengajaran. Pengajaran sebagai suatu proses transfer ilmu belaka, sedang pendidikan merupakan transformasi nilai dan pembentukan kepribadian dengan segala aspek potensi yang menyertainya.

Dari pengertian pendidikan tersebut ada kata kunci yang menjadi objek pembicaraan yaitu manusia. Hal ini berkaitan dengan pertanyaan siapa yang harus dididik. Manusia yang menjadi sentral pembahasan dalam pendidikan, ia dibentuk agar menjadi dewasa dan dapat memaksimalkan potensi (kemampuan) dasar yang dimilikinya sejak ia lahir kedunia. Secara psikis (kejiawaan) setiap manusia yang lahir ke dunia (keadaan normal red) ia mempunya potensi dasar asasi yang dibawanya yaitu: ${ }^{7}$

\footnotetext{
${ }^{6}$ Nasution. Teknologi Pendidikan. Cet 8(Jakarta: Bumi Aksara, 2015) hlm 4

${ }^{7}$ Maswan dan khoirul Muslimin. Teknologi .... HIm 4
} 
EVALUASI, 3(2), September 2019, ISSN 2580-3387 (print) |

ISSN 2615-2886 (online)

http://doi.org/10.32478/evaluasi.v3i2.296

1) Potensi pengindraan, berupa penglihatan (mata), pendengaran (telinga), penciuman (hidung), pengecapan (lidah), dan perabaan (kulit)

2) Potensi pikiran (otak).

3) Potensi karsa (kemauan/keinginan),

4) Potensi cipta (gagasan/konsep)

5) Petensi karya (berbuat/bekerja) dan

6) Potensi budi nurani atau hati nurani (perasaan/emosi)

Dua petensi besar manusia yaitu fisik dan psikis dibangun dan dikembangkan secara simultan, terkait satu sama lain yang menjadi satu kesatuan utuh. Manusia mampu dikenal orang lain sebagai manusia, manakala dia mempunyai keunggulan kemampuan pilar pisik dan psikis cukup baik dan normal.

Perangkat potensi di atas masing-masing manusia pada prinsipnya hampir sama, yang membedakan adalah genetis dari orangtuanya. Semua anak manusia terlahir dalam keadaan tidak berdaya (tidak punya kemampuan apa-apa) baik secara fisik dan psikis, kalau menurut pandangan agama anak terlahir dalam keadaan fitrah (suci bersih) dan dhaif (lemah). Apa dapat berkembang, maka potensi dasar itu harus dibangun, dibentuk, diajari, dilatih, dididik, ditunjukkan, diarahkan, dan dibimbing oleh orang-orang dewasa yang ada disekitarnya ${ }^{8}$

Sedangkan definisi teknologi pendidikan, ada beberapa pendapat:

a) Prof Sutomo dan Drs. Sugito, M.Pd, teknologi pendidikan adalah proses yang kompleks dan terpadu untuk menganalisi serta memecahkan masalah belajar atau pendidikan manusia.

${ }^{8}$ Ibid hlm 6 
EVALUASI, 3(2), September 2019, ISSN 2580-3387 (print) |

ISSN 2615-2886 (online)

http://doi.org/10.32478/evaluasi.v3i2.296

b) Mackenzie, dkk. Teknologi pendidikan yaitu suatu usaha mengembangkan alat untuk mencapai atau menemukan solusi permasalahan. Jadi tidak perlu menyiratkan penggunaan mesin, akan tetapi lebih banyak penggunaan unsur berpikir dan menggunakan pengetahuan ilmiah. ${ }^{9}$

Dengan demikian definisi teknologi pendidikan adalah proses yang rumit dan terpadu, melibatkan orang, prosedur, gagasan, peralatan, dan organisasi untuk menganalisis dan mengolah masalah, kemudian menggunakan, mengevaluasi, dan mengelola seluruh upaya pemecahan masalahnya yang termasuk dalam seluruh aspek belajar (manusia) ${ }^{10}$

Jadi teknologi pendidikan adalah segala usaha untuk memecahkan masalah pendidikan. Lebih detail dapat diuraikan bahwa:

1) Teknologi pendidikan lebih dari perangkat keras. la terdiri dari desain dan lingkungan yang melibatkan pelajar

2) Teknologi dapat juga terdiri dari segala teknik atau metode yang dapat dipercaya untuk melibatkan pelajaran; strategi belajar kognitif dan keterampilan berpikir kritis

3) Belajar teknologi bisa dilingkungan manapun yang melibatkan siswa belajar secara aktif, konstruktif, autentik dan kooperatif serta bertujuan. ${ }^{11}$

Teknologi pendidikan bukanlah seledar mesin dan orang. Teknologi pendidikan merupakan perpaduan yang kompleks dari organisasi manusia dan mesin, ide, prosedur dan pengelolaan sistem pendidikan.

\footnotetext{
${ }^{9}$ Maswan dan Khoirul Muslimin teknilogi ... hlm 25

${ }^{10}$ Ibid hlm 26

${ }^{11}$ Ibid hlm 29
} 
EVALUASI, 3(2), September 2019, ISSN 2580-3387 (print) |

ISSN 2615-2886 (online)

http://doi.org/10.32478/evaluasi.v3i2.296

Teknologi pendidikan memperluas bidang-bidang pengembangan teoritik, riset dan implementasinya dalam bidang pendidikan. Jika diterapkan dalam dunia pendidikan, teknologi merupakan proses yang kompleks lagi terpadu untuk menganalisis masalah mencari jalan pemecahannya, mengimplemtasikan, mengelola dan mengontrol serta mengevaluasi pemecahan masalah terhadap masalah masalah pendidikan. ${ }^{12}$

Dengan demikian teknologi pendidikan memiliki peran yang signifikan dalam dunia pendidikan baik dari segi pelaksanaan dan pengembangannya.

\section{Mutu Pendidikan}

Secara umum, mutu mengandung makna derajat (tingkat) keunggulan suatu produk (hasil kerja atau upaya) baik berupa barang maupun jasa, baik yang tangible maupun yang intangible. Mutu adalah sebuah hal yang berhubungan dengan gairah dan harga diri. Mutu terkadang dianggap sebagai sebuah konsep yang penuh tekateki, dianggap hal yang membingungkan dan sulit untuk diukur. Mutu terkadang juga menimbulkan perbedaan dan pertentangan antara pendapat yang satu dan pendapat yang lain sehingga menimbulkan persepsi yang berbeda dari para pakar. ${ }^{13}$

Mutu memiliki pengertian yang beragam dan memiliki implikasi yang berbeda jika diterapkan pada sesuatu tergantung pada barang apa yang dihasilkan, dipakai dan anggapan orang. Berikut beberapa pendapat tentang mutu: ${ }^{14}$

\footnotetext{
${ }^{12} \mathrm{Ibid}$ hlm 30

${ }^{13}$ Nur Zazin. Gerakan menata mutu pendidikan teori dan aplikasi. (Jogjakarta: ArRuzz Media, 2011) hlm 54

${ }^{14}$ Ibid hlm 54-55
} 
EVALUASI, 3(2), September 2019, ISSN 2580-3387 (print) |

ISSN 2615-2886 (online)

http://doi.org/10.32478/evaluasi.v3i2.296

a. Gasper, berpendapat mutu definisi konvensional berarti karakteristik langsung dari suatu produk, sedangkan definisi modern berarti segala sesuatu yang mampu memenuhi keinginan atau kebutuhan pelanggan

b. Arcaro, berpendapat mutu sebuah derajat variasi yang terduga standar yang digunakan dan memiliki ketergantungan pada biaya yang rendah

c. Daming, berpendapat mutu berarti pemecahan untuk mencapai penyempurnaan terus menerus

d. Juran, berpendapat, mutu diartikan sebagai kesesuaian penggunaan atau tepat untuk dipakai

Dalam konteks mutu pendidikan, konsep mutu adalah elite karena hanya sedikit institusi yang dapat memberikan pengalaman dengan mutu tinggi kepada peserta didik

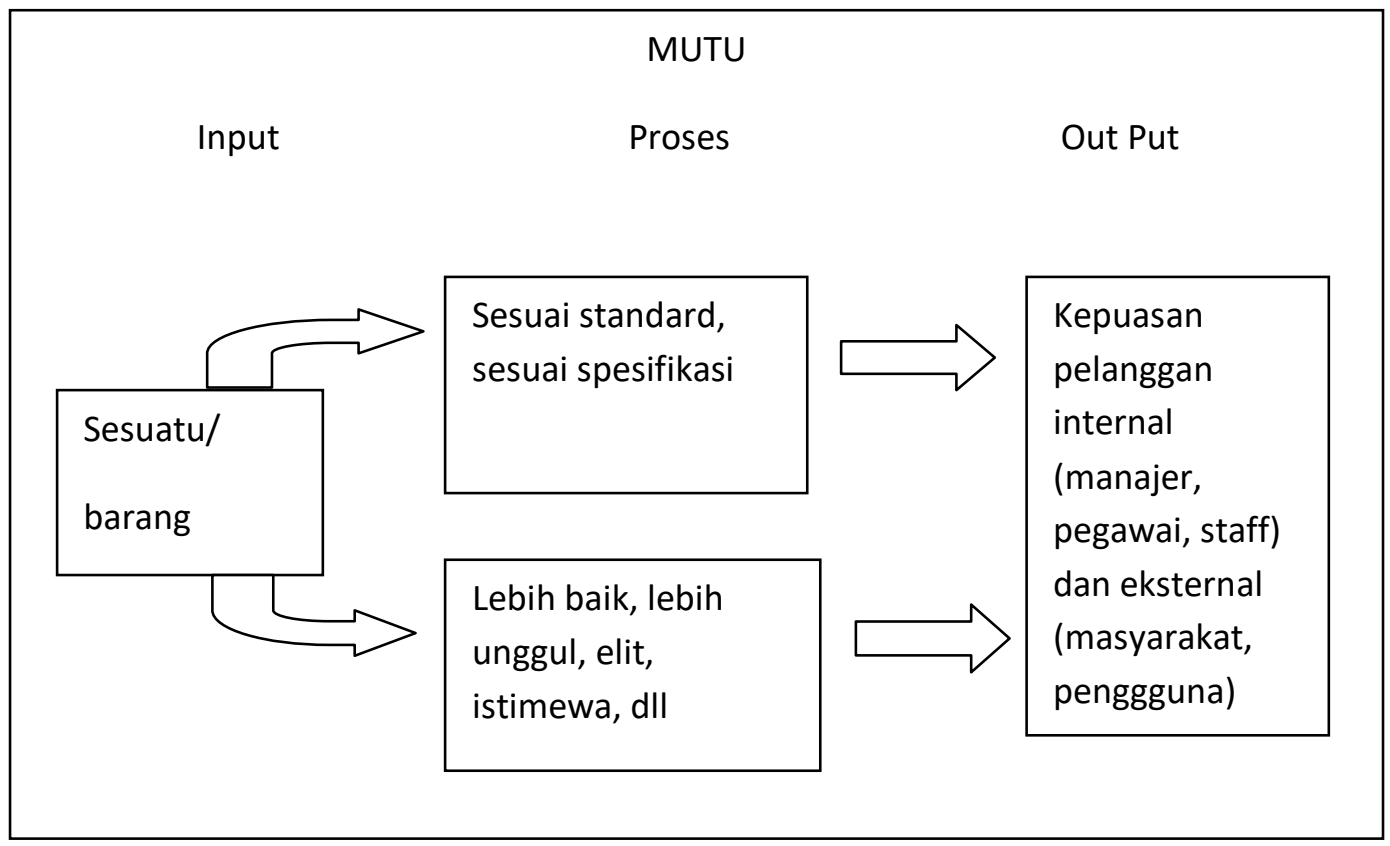

Gambar 1. Gambar memahami definisi makna mutu 
EVALUASI, 3(2), September 2019, ISSN 2580-3387 (print) |

ISSN 2615-2886 (online)

http://doi.org/10.32478/evaluasi.v3i2.296

Dalam perspektif pendidikan, mutu dapat dilihat dari sisi prestasi siswa, proses pembelajaran, kemampuan lulusan dalam mengembangkan potensinya dimasyarakat, serta dalam hal memecahkan masalah dan berpikir kritis

Dengan demikian, untuk mengetahui pendidikan yang bermutu, perlu dikaji mutu dari segi proses, sebagaimana produk atau maupun sisi internal dan kesesuaian. Dari segi proses, mutu pendidikan berarti keefektifan dan efesiensi seluruh faktor yang berperan dalam proses pendidikan. Faktor tersebut sebagai berikut: ${ }^{15}$

1) Kualitas guru

2) Sarana dan prasana

3) Suasana belajar

4) Kurikulum yang dilaksanakan

5) Pengelolaan sekolah

Secara efesiensi internal, pendidikan yang bermutu adalah pendidikan yang tujuan institusi dan kurikulernya dapat tercapai. Sedangkan, jika dilihat dari kesesuaian, pendidikan yang bermutu adalah pendidikan yang kemampuan lulusannya sesuai dengan kebutuhan tenaga kerja di pasaran dan sesuai dengan kriteria pada pengguna lulusan

Mutu pendidikan secara multidimensi meliputi aspek mutu input, proses, dan output. Oleh karenanya, pengembangan pencapaian mutu harus secara holistic dimulai dari input, proses, dan output. Dengan demikian. Mutu pendidikan adalah kebermutuan dari berbagai layanan institusi pendidikan kepada siswa maupun staf pengajar untuk terjadinya proses pendidikan yang bermutu sehingga akan menghasilkan lulusan yang mempunyai kemampuan,

\footnotetext{
${ }^{15}$ Nur Zazin gerakan menata mutu .... HIm 66
} 
EVALUASI, 3(2), September 2019, ISSN 2580-3387 (print) |

ISSN 2615-2886 (online)

http://doi.org/10.32478/evaluasi.v3i2.296

keterampilan, dan pengetahuan yang sesuai dengan kebutuhan untuk terjun ke lingkungan masyarakat ${ }^{16}$

Sehingga bisa dipahami bahwa mutu pendidikan itu meliputi aspek input, proses dan output

Mutu pendidikan dapat dilihat dari lima macam penilaian sebagai berikut: ${ }^{17}$

1) Prestasi siswa yang dihubungkan dengan norma nasional dan agama dengan menggunakan skala nilai

2) Prestasi siswa yang berhubungan dengan kemampuan

3) Kualitas belajar mengajar

4) Kualitas mengajar

5) Kinerja sekolah

\section{METODE PENELITIAN}

Metode penelitian pada artikel ini menggunakan kualitatif. Sedangkan Penyajian data menggunakan deskriptif analisis dan dirancang dengan menggunakan pendekatan pustaka (library research) dengan mencari beberapa literatur yang membahas tentang teknologi pendidikan dan mutu pendidikan

\section{HASIL DAN PEMBAHASAN}

Dari paparan teknologi dan mutu pendidikan pada pembahasan sebelumnya, bahwa adanya relevansi atau keterkaitan antara teknologi pendidikan dengan mutu pendidikan, karena mutu pendidikan berkenaan dengan segala yang menjadi tercapainya pendidikan bermutu

\footnotetext{
${ }^{16}$ Ibid

${ }^{17}$ Ibid hlm 67
} 
EVALUASI, 3(2), September 2019, ISSN 2580-3387 (print) |

ISSN 2615-2886 (online)

http://doi.org/10.32478/evaluasi.v3i2.296

baik dari segi prestasi siswa, kualitas mengajar, maupun kinerja sekolah bisa tercapai dengan baik melalui pendekatan teknologi pendidikan.

Sebagaimana diuraikan sebelumnya bahwa teknologi pendidikan adalah proses yang rumit dan terpadu, melibatkan orang, prosedur, gagasan, peralatan, dan organisasi untuk menganalisis dan mengolah masalah, kemudian menggunakan, mengevaluasi, dan mengelola seluruh upaya pemecahan masalahnya yang termasuk dalam seluruh aspek belajar (manusia) ${ }^{18}$

Dilihat definisi tersebut menunjukkan bahwa permasalahan yang titik tekannya berkenaan dalam pelaksanaan pendidikan termasuk didalamnya masalah belajar mengajar, maka teknologi pendididikan merupakan upaya yang tepat, karena melibatkan orang-orang yang memiliki peran penting di permasalahan pendidikan tersebut, kemudian diatur dengan prosedur yang ada dan tahap selanjutnya diorganisasi untuk dianalisis dan dicarikan solusi pemecahannya.

Menurut Ely (1979), pada umumnya teknologi pendidikan dianggap mempunyai potensi untuk: ${ }^{19}$

1. Meningkatkan produktivitas pendidikan dengan jalan:

a. Mempercepat tahap belajar (rate of learning)

b. Membantu guru untuk menggunakan waktunya secara lebih baik

c. Mengurangi beban guru dalam menyajikan informasi, sehingga guru dapat lebih banyak membina dan mengembangkan belajar anak

2. Memberikan kemungkinan pendidikan yang lebih individual dengan jalan:

${ }^{18}$ Nur Zazin. Gerakan .......h/m 26

${ }^{19}$ Maswan dan Khoirul Mukminin. Teknologi pendidikan .... HIm 38-39 
EVALUASI, 3(2), September 2019, ISSN 2580-3387 (print) |

ISSN 2615-2886 (online)

http://doi.org/10.32478/evaluasi.v3i2.296

a. Mengurangi control guru yang kaku dan tradisional

b. Memberikan kesempataan anak berkembang sesuai dengan kemampuan

3. Memberikan dasar yang lebih ilmiah terhadap pengajaran, dengan jalan:

a. Perencanaan program pengajaran yang lebih sistematis

b. Pengembangan bahan pengajaran yang dilandasi penelitian tentang perilaku

4. Lebih memantapkan pengajaran, dengan jalan:

a. Meningkatkan kapabilitas manusia dengan berbagai media komunikasi

b. Penyajian informasi dan data secara lebih kongkret

5. Memungkinkan belajar secara seketika (immediacy of learning) karena dapat:

a. Mengurangi jurang pemisah antara pelajaran did alam dan diluar sekolah

b. Memberikan pengetahuan langsung

6. Memungkinkan penyajian pendidikan lebih luas, terutama adanya media massa, dengana jalan:

a. Pemanfaatan bersama (secara lebih luas) tenaga atau kejadian yang langka

b. Penyajian informasi menembus batas geografis

Hal ini menunjukkan teknologi pendidikan memiliki peran dan posisi yang strategis dalam rangka upaya untuk meningkatkan mutu pendidikan yang diharapkan oleh pemerintah secara umum dan lembaga pendidikan secara khusus. 
EVALUASI, 3(2), September 2019, ISSN 2580-3387 (print) |

ISSN 2615-2886 (online)

http://doi.org/10.32478/evaluasi.v3i2.296

\section{E. PENUTUP}

Dari uraian diatas dapat disimpulkan, teknologi pendidikan merupakan perpaduan yang kompleks dari organisasi manusia dan mesin, ide, prosedur dan pengelolaan sistem pendidikan. Secara umum, mutu mengandung makna derajat (tingkat) keunggulan suatu produk (hasil kerja atau upaya) baik berupa barang maupun jasa, baik yang tangible maupun yang intangible. Sedangkan dalam perspektif pendidikan, mutu dapat dilihat dari sisi prestasi siswa, proses pembelajaran, kemampuan lulusan dalam mengembangkan potensinya dimasyarakat, serta dalam hal memecahkan masalah dan berpikir kritis

Adanya relevansi atau keterkaitan antara teknologi pendidikan dengan mutu pendidikan, karena mutu pendidikan berkenaan dengan segala yang menjadi tercapainya pendidikan bermutu baik dari segi prestasi siswa, kualitas mengajar, maupun kinerja sekolah bisa tercapai dengan baik melalui pendekatan teknologi pendidikan. Karena dengan teknolgi pendidikan melibatkan orang-orang yang memiliki peran penting di permasalahan pendidikan, kemudian diatur dengan prosedur yang ada dan tahap selanjutnya diorganiasi untuk dianalisis dan dicarikan solusi pemecahannya.

\section{DAFTAR RUJUKAN}

Hadis, Abdul dan Nurhayati B. 2010. Manajemen Mutu Pendidikan. Bandung: Alfabeta.

Maswan dan Khoirul Muslimin. 2017. Teknologi pendidikan: penerapan pembelajaran yang sistematis. Yogyakarta: Pustaka pelajar

Nasution. 2015.Teknologi Pendidikan. Cet 8. Jakarta: Bumi Aksara.

Nur Zazin. 2011. Gerakan menata mutu pendidikan teori dan aplikasi. Jogjakarta: Ar-Ruzz Media

Zamroni. 2011. DInamika Peningkatan Mutu cet 1. Yogyakarta: Gavin Kalam Utama. 